\title{
O desafio da sustentabilidade nos transportes públicos e na mobilidade urbana em face da pandemia da COVID-19 na realidade brasileira
}

( Mauricio Oliveira de Andrade

Departamento de Engenharia Civil, Universidade Federal de Pernambuco, Brasil. ORCID: https://orcid.org/oooo-0002-7377-7668

\author{
Oswaldo Cavalcanti da Costa Lima Neto \\ Departamento de Engenharia Civil, Universidade Federal de Pernambuco, Brasil. \\ ORCID: https://orcid.org/oooo-0003-1007-5359
}

\author{
Ligia Rabay \\ Departamento de Engenharia Civil, Universidade Federal de Pernambuco, Brasil. \\ ORCID: https://orcid.org/0000-0003-0159-6953
}

Recibido: 30 de marzo de 2021. Aceptado: 29 de junio de 2021.

\begin{abstract}
Resumo
A demanda por deslocamentos reduziu-se globalmente, com impactos sem precedentes no transporte público pela pandemia da Covid-19. As razões vinculam-se a medidas de restrições a aglomerações, a decisões individuais de evitar viagens para diminuir exposição ao risco, e como consequência o aumento no uso do automóvel. O Brasil que apresentava tendência de redução de demanda enfrenta a pandemia como um problema adicional que colocou em risco a sustentabilidade financeira dos serviços. Nesse contexto de perplexidade, foi promovido um Fórum de Discussão onde buscou-se obter elementos para propor diretrizes e ações estratégicas para apoiar o Poder Público e os operadores a enfrentarem esse desafio. Para sintetizar, estruturar e hierarquizar problemas, para superar a insustentabilidade do modelo atual de transporte público agravado pela pandemia foram aplicados instrumentos combinados de análise de causa e efeito de Ishikawa, de análise de Pareto e de planejamento estratégico pela Matriz de Marco Lógico. Estabeleceu-se como objetivo superior a oferta de transportes seguros e economicamente sustentáveis e objetivos específicos de redução de risco à exposição, reformulação das redes com ajuste oferta-demanda, apoio a modos ativos e disponibilização de informações por aplicativos. Essas estratégicas exigem um novo papel do poder público e novas formas de financiamento ao transporte.
\end{abstract}




\title{
The challenge of sustainability in public transport and urban mobility in face of the covid-19 pandemic in Brazilian reality
}

\begin{abstract}
Travel demand has reduced globally, with unprecedented impacts on public transport since the Covid-19 pandemic. The reasons are linked to measures to restrict agglomerations, to personal decisions to prevent travel to reduce risk exposure, and as a consequence the use of cars has increased. Brazil in a trend of demand reduction faces the pandemic as an additional problem that put the financial sustainability of services at risk. In this context of perplexity, a Discussion Forum was promoted to extract ideas to propose guidelines and strategic actions to support governments and operators to confront this challenge. To synthesize, structure and prioritize problems to overcome the unsustainability of the current model of public transport aggravated by the pandemic, combined instruments for the analysis of cause and effect by Ishikawa, Pareto analysis and strategic planning by Logical Framework were applied. It was established as a superior objective the supply of safe and economically sustainable transport and specific objectives of reducing risk to exposure, reformulating the networks with supply-demand adjustment, supporting active modes and making information available through apps. These strategies require a new role for the governments and new ways of transportation funding.
\end{abstract}

Keywords: Covid-19. Sustainable Mobility. Public Transport. Transport Demand.

Palabras clave: Covid-19. Movilidad sustentable. Transporte público. Demanda de transporte.

\section{Introdução}

A demanda por deslocamentos urbanos reduziu-se, em nível mundial, com impactos sem precedentes no setor de transportes a partir da pandemia da Covid-19 (Zhang, 2020). Milhões de pessoas foram colocadas em lockdown na tentativa de reduzir a transmissão do vírus (Saadat et al. 2020). No entanto, tal redução de demanda não se deu de modo uniforme em todos os modos de transportes (Bucsky, 2020; Almlöf et al., 2021). Astroza et al. (2020) e Eisenmann et al. (2021) sinalizam que foi no transporte público urbano em que se registraram as maiores reduções. Recursos financeiros públicos têm sido necessários para manter serviços essenciais com baixa demanda e com necessidade de distanciamento social (Vickerman, 2021). Os modos individuais de deslocamento como automóveis e bicicletas substituíram muitas viagens por transporte público (Bucs$\mathrm{ky}, 2020$ ). As principais razões vinculam-se a medidas governamentais de restrições a aglomerações, a decisões individuais de evitar viagens para diminuir exposição ao risco de contaminação (Tirachini; Cats, 2020; Rodrigues, 2020; Hausler et al., 2020) e a imposição de novas regulações que impactam na capacidade dos serviços (Gkiotsalitis; Cats, 2021). Como consequência, entre outras, a pandemia mudou o estilo de vida das pessoas, causou graves perdas de empregos e fechamento de empresas (Saadat et al. 2020). Além disso, acelerou o trabalho remoto, que produziu uma das mais rápidas mudanças observadas na vida pessoal e profissional de grande parte da sociedade em todo o mundo (Hiselius e Arbfalk, 2021). Também no curto prazo aumentou o uso de modos individuais de deslocamentos.

Em termos globais, o impacto da pandemia sobre o transporte público varia com o nível de disseminação da doença. Estimativas preliminares apontam redução de uso durante os períodos de lockdown de 80 a 90\% nas principais cidades da China, Iran e Estados Unidos (UITP, 2020a). Apesar da redução média de demanda de 70 a 90\% em várias cidades do mundo, os custos para os operadores aumentam com necessidades 
adicionais de implementar controles de higiene e de saúde e reduzir o número de passageiros por veículos (Hausler et al., 2020). Segundo Bouffanais e Lim (2020), os principais fatores que têm afetado o uso do transporte público são a duração do contato e a proximidade das pessoas, além das condições ambientais, principalmente no que se refere à renovação do ar. Enquanto procedimentos de segurança sanitária para mitigar esses fatores têm sido reduzidos com relação às preocupações do início da pandemia, muitos passageiros permanecem relutantes em usar os serviços. Assim, percebe-se um grande nível de incerteza em se fazer previsão de demandas nos períodos durante e pós-pandemia (Gkiotsalitis e Cats, 2021).

No Brasil, como tendência observada desde 2014, a quantidade de passageiros equivalentes anuais nos sistemas de transporte público urbano por ônibus das cidades de São Paulo, Rio de Janeiro, Salvador, Belo Horizonte, Porto Alegre, Curitiba, Fortaleza, Recife e Goiânia tem diminuído continuamente (Araújo, 2019). Segundo a NTU et al. (2020) dessa perda de demanda, parte migrou para modos individuais e parte passou a andar a pé por não ter condições de pagar a tarifa. É nesse contexto de redução de demanda e de qualidade nos transportes públicos, reforçado pelo modelo de tarifação focado unicamente no usuário e pela inexistência de recursos suficientes para o financiamento do setor (MDT, 2020), que eclode a pandemia da Covid-19. Levantamentos da Associação Nacional das Empresas de Transportes Urbanos (NTU) mostram que nos primeiros quarenta e cinco dias da pandemia, em 314 cidades houve redução de oferta e em 181 delas os serviços foram paralisados. Em termos de demanda em nível nacional, o número de passageiros foi reduzido em média em $80 \%$, acompanhado de uma redução de oferta média de $25 \%$. Nos maiores sistemas que operam nas capitais brasileiras, a redução de demanda foi da ordem de $70 \%$ com redução de oferta de $50 \%$. Como a tarifa paga pelo passageiro é quase a única forma de financiar o transporte público, fica difícil manter os sistemas operando com essas restrições de receita com aumento de custos. No Brasil, apenas 11 sistemas de transportes coletivos dispõem de algum nível de subsídio público, em sua maioria, para custear gratuidades de estudantes, idosos e pessoas com necessidades especiais (NTU, 2020). Nesta mesma direção, a Associação Internacional de Transporte Público (UITP) considera o principal desafio do setor, a manutenção de altos níveis de serviço, em um ambiente de distanciamento seguro dos usuários (UITP, 2020b).

Pelo lado do usuário, nesta fase de pandemia, problemas de superlotação e de dificuldades em manter um isolamento social mínimo, apesar da obrigatoriedade do uso de máscaras faciais e de controle da ocupação têm sido fartamente documentados e denunciados em todo o Brasil. Segundo manifesto do Movimento do Direito ao Transporte (MDT), esses problemas demonstram a desarticulação e ineficácia da ação do Estado em prover transporte, como serviço público essencial e Direito Constitucional Social. As perspectivas econômicas projetam um quadro de recessão e elevação do desemprego, reforçando a necessidade de serviços de transportes públicos, como pilares do enfrentamento da pandemia. É necessário ampliar serviços, reduzir tarifas, atender aos desempregados, contribuindo assim para a reconstrução do país (MDT, 2020).

Mesmo que, a extensão e a duração das mudanças produzidas pela presente crise ainda não estejam completamente claras, não resta dúvidas que produziram profundos impactos nos padrões de viagens (Hiselius e Arbfalk, 2021). Assim, com o retorno à normalidade, novos procedimentos operacionais e de planejamento são necessários para recuperar a confiança no transporte público (Gkiotsalitis e Cats, 2021). Gestores políticos e autoridades de transportes e de saúde em conjunto deveriam colaborar para promover políticas e procedimentos, que sejam eficientes em proteger usuários de transporte e pessoal de operação (Gaskin, 2021). 
Nesse contexto de perplexidade, com novas necessidades impostas pela pandemia da Covid-19 aos sistemas de mobilidade urbana e de transporte público já em crise de sustentabilidade no Brasil, foi promovido um Fórum de Discussão pelo Programa de Pós-graduação em Engenharia Civil da Universidade Federal de Pernambuco (UFPE).

Nesse fórum buscou-se obter elementos para produzir um documento que proponha diretrizes e ações estratégicas que possam auxiliar o Poder Público e os operadores de transporte a enfrentar esse desafio, a partir do olhar de diferentes atores em contextos e geografias diferentes. Participaram, além de pesquisadores de várias universidades latino-americanas e europeias, gestores dos serviços de transportes das principais capitais brasileiras, representantes regionais e nacionais de associações de empresas operadoras e representantes de organizações sociais com interesse sobre o tema.

O Fórum aconteceu na forma de oito webinars temáticos, em que as questões foram abordadas de forma livre dentro da ótica de cada expositor. Como pressupostos, as discussões deveriam focar nos mais vulneráveis, na responsabilidade pública, em soluções de curto e médio prazo, na quebra de paradigmas e na sustentabilidade econômico-financeira dos serviços. Coube à coordenação sintetizar os resultados, extrair e estruturar as ideias centrais para, por meio da aplicação de técnicas de planejamento estratégico, sugerir uma agenda política para superação dos problemas crônicos e os novos decorrentes da crise da pandemia.

A busca da mobilidade sustentável nas últimas décadas requer soluções holísticas, por meio de abordagens inter e multidisciplinares e que reconheçam a complexidade das relações envolvidas (Holden et al., 2020). Assim, a questão central proposta aos expositores e debatedores teve uma formulação dual: (i) como superar no curto e médio prazo - partindo de um modelo em crise e com perda de passageiros há anos, provavelmente para o transporte individual, e dadas as precárias condições infraestruturais para viabilizar em escala mais ampla meios ativos de transporte - o desafio adicional de aumentar a segurança sanitária no transporte público, em um cenário de dificuldades de financiamento associada a aumentos de custos operacionais?; e (ii) como reduzir os riscos de exposição da população à contaminação do vírus a custos financiáveis pela sociedade?

Como síntese argumentativa inicial, percebe-se a crise da Covid-19 como oportunidade para promover mudanças no planejamento e na gestão dos transportes públicos, que enfrentem as questões crônicas já observadas no modelo vigente no Brasil e as novas trazidas pelo contexto da pandemia. São necessárias mudanças radicais nos níveis estratégico, tático e operacional para superar as barreiras para ampliar a utilização do transporte público de forma atrativa e segura para todos.

Como objetivo central propõe-se do resultado do Fórum, definir objetivos, metas e estratégias para mitigar os riscos potenciais de proliferação da Covid-19 e tentar equilibrar os sistemas de transportes coletivos, essenciais para vida cotidiana principalmente dos mais pobres, tentando salvá-los da falência, apontando barreiras econômicas, sociais e políticas que precisam ser superadas. Os objetivos e metas serão qualificados em estratégicos (reformas institucionais), táticos (reformas no planejamento) e operacionais, a partir dos níveis de responsabilidade envolvidos. Ressalte-se que se busca apontar saídas não diretamente para salvar empresas, mas para reequilibrar todo o sistema de mobilidade e de transporte público.

Como objetivos específicos propõem-se: i) caracterizar a partir do Fórum, o problema central que afeta os sistemas de mobilidade e de transportes públicos agravados pela pandemia em cidades brasileiras; ii) apontar causas e efeitos sobre os usuários e a cidade; e iii) definir uma matriz de planejamento com objetivos, indicadores/metas e 
pressupostos para superar os problemas identificados. Ao final, ressalta-se que o presente estudo é uma tentativa metodológica de como propor uma política de transporte a partir de ideias livremente expostas por pesquisadores, operadores, gestores e políticos que lidam com a problemática dos transportes e da mobilidade urbana.

\section{Revisão da literatura}

Em princípio há uma grande lacuna de conhecimento científico acerca do potencial do impacto da pandemia no transporte público, em metodologias aplicáveis no apoio a decisões de políticas e em modelos que possam dar eficientemente suporte ao planejamento da mobilidade em razão desse enorme desafio (Konstantinos e Oded, 2021; Zhang, 2021). A maior parte dos estudos revisados apenas apresenta conclusões preliminares. É necessário que o mundo se prepare para o chamado "novo normal" (Zhang, 2020). Bucsky (2020) coloca algumas questões chave: As mudanças em mobilidade decorrentes da pandemia terão efeitos de longo prazo? Após a normalização as tendências anteriores retornam? Quais mudanças serão mais permanentes? Estaríamos nos aproximando ou distanciando dos paradigmas da mobilidade sustentável como propostos por Banister (2008)?

Como estratégias para formulação de políticas para lidar como o problema, Zhang (2020) propôs uma nova abordagem expressada por um conjunto de ideias-força para combater a COVID-19 atual e pandemias futuras. Com base nesta abordagem, o autor estrutura suas recomendações em quatro categorias de estratégias: i) planejar eficientemente as ações, proteger usuários e empregados, prover informações confiáveis em tempo real e assegurar recursos financeiros adicionais; ii) Evitar que os operadores realizem viagens em veículos lotados e com usuários sem máscaras, os usuários precisam evitar viagens desnecessárias e ajustar suas viagens em função dos tempos para reduzir riscos de infecção, o governo precisa ajustar as políticas de restrições com uma abordagem interdisciplinar e em colaboração com outras áreas; iii) aos que precisam viajar, mudar de modo para reduzir riscos de infecção, compartilhar informações e recursos é essencial para decisões e ações coletivas; os governos precisam mudar a governança tradicional para uma governança sensível à pandemia envolvendo todos os stakeholders; incorporar meios de deslocamento da economia compartilhada para suprir áreas deficitárias e carência de recursos por de meio de desregulamentação temporária; iv) substituir ou parar atividades que envolvem deslocamentos quando a pandemia se agrava com regulações e proibições apoiadas por medidas de proteção econômica aos afetados.

Oum e Wang (2020) elaboraram um modelo relacionando o ponto socialmente ótimo das políticas de restrição a viagens com os níveis de congestionamento, considerando os custos externos que causam falhas de mercado. Os resultados apontam que: i) os indivíduos não internalizam nas decisões de viagem os custos externos dos riscos de contaminar outros e de congestionar o sistema de saúde; ii) o tempo do lockdown socialmente ideal é sempre maior que a duração aceitável pelos indivíduos; iii) a restrição de viagens e o valor da pena de infração devem ser maiores nas áreas mais densas e nas cidades maiores pelos maiores riscos; iv) quando um governo subsidia ou assume todas as despesas médicas de pacientes infectados, são necessárias restrições de viagem mais rígidas com penalidades mais pesadas.

Bouffnais e Lim (2020) relatam experiências em Paris, Singapura, Taipei e Coréia do Sul onde se tentou identificar situações potenciais nos transportes públicos para a proliferação da COVID-19. Essas experiências se baseiam em rastreamento dos usuários de transporte público, levantando o tempo de viagem (duração do contato), proximidade 
física e condições ambientais, tentando extrair um nível de ocupação que respeite as normas de distanciamento social. Concluem recomendando que mais financiamento é necessário para acelerar estudos sobre movimentos humanos e suas interações em pontos de grande risco de disseminação de epidemias, como nos sistemas de transportes e nos seus hubs.

Aloi et al. (2020) analisaram o efeito das medidas de mobilidade urbana na quarentena em Santander na Espanha em março de 2020, revelando uma queda geral da mobilidade de $76 \%$ e do transporte público em $93 \%$. O relatório do Center for Future Mobility (Hausler et al., 2020), destaca que o número de passageiros no transporte público caiu de 70 a $90 \%$ nas principais cidades do mundo. Almlof et al. (2021) analisaram a propensão a parar de utilizar o transporte público durante a Covid-19 para portadores de 1,8 milhão de smartcards em Estocolmo. Foram construídos dois modelos de regressão logística buscando explicar a probabilidade do afastamento do transporte público em relação a dados socioeconômicos. O primeiro modelo analisou o impacto de fatores socioeconômicos e os resultados demonstram que a redução do uso está associada a áreas com população de status econômico mais elevado. O segundo modelo dividiu os usuários em clusters e como resultado apontou que os moradores rurais eram os que apresentaram maiores chances de continuar utilizando o transporte público, seguido dos mais pobres. Esses resultados podem conduzir a políticas de ajustar a oferta para onde as necessidades são maiores, ao invés de assumir que as demandas na rede são igualmente distribuídas.

Dai et al. (2021) analisaram as politicas de gratuidades adotadas nos metrôs em Hangzhou, Ningbo e Xiamen na China, para atrair passageiros de volta ao transporte público. Os resultados mostram que a política de viagens gratuitas nos horários de pico em Hangzhou não obteve efeito significativo na demanda; as políticas "mais viagens, mais descontos" e as viagens gratuitas fora dos horários de pico em Ningbo aumentaram a demanda em $24 \%$ no primeiro mês; e a política de viagem gratuita nos finais de semana em Xiamen aumentou o número de passageiros do metrô em 2,3 vezes.

Eisenmann et al. (2021) pesquisaram as mudanças gerais e individuais no uso dos meios de transporte e nas atitudes em relação às escolhas, com foco na bicicleta, no carro e no transporte público durante a pandemia e o lockdown na Alemanha. Além disso, investigaram as mudanças na percepção das opções de mobilidade individual com foco em domicílios sem carro. Os resultados indicam que o transporte público perdeu espaço durante o período restrito de bloqueio, enquanto os modos individuais de transporte, especialmente o carro particular, tornaram-se mais importantes.

Hiselius e Arnfalk (2021) analisaram o impacto sobre o trabalho e os padrões de viagem nas agências públicas suecas. Os resultados apontam que $86 \%$ dos pesquisados mudaram suas viagens ao trabalho, deixando claro que há um grande potencial nas ferramentas digitais para influenciar decisões de viagens pendulares e viagens de negócios. Heineke et al. (2020) apontam mudanças nos motivos das escolhas modais para viagens ao trabalho a partir da crise da Covid-19 com a importância primordial dada ao risco de infecção e a perda da importância dos custos da viagem, como destaca a Figura 1. Além de segurança sanitária, os consumidores estão cada vez mais focados nos meios digitais e na sustentabilidade. Segundo os autores, acesso a opções de microacessibilidade como bicicletas e caminhadas se tornará crescentemente importante. 


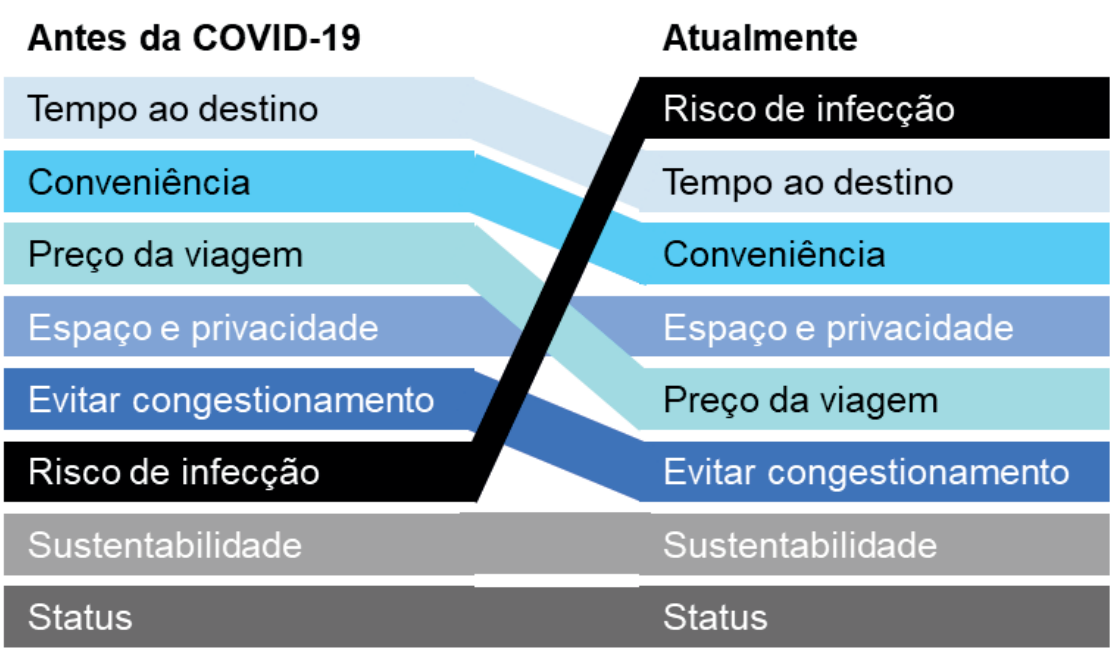

Figura 1. Motivos de Escolhas Modais ao trabalho na Suécia. Fonte: Heineke et al. (2020).

Vickerman (2021) argumenta que não é provável que as formas atuais de prestação de serviços de transportes públicos se ajustem ao novo normal pós-pandemia em função do crescimento do trabalho remoto e do receio de espaços congestionados. Argumenta ainda que isso pode significar o fim do modelo atual de transporte público desregulado que prevalece no Reino Unido e exigir um grande repensar da forma de ofertar um sistema de transporte eficiente e eficaz. Tal solução dependerá da interação das normas privadas e sociais e da construção da confiança pública.

Com relação ao Brasil, um dos países do mundo que mais vem sofrendo com a pandemia, o Movimento Nacional pelo Direito ao Transporte Público de Qualidade para Todos- (MDT) (2020) propõe em manifesto que se estabeleça um Pacto de Combate à Crise com a participação das empresas operadoras, trabalhadores e sociedade civil, tendo como objetivo garantia da sobrevivência do serviço de transporte público, garantindo empregos, melhorias de serviços e a implementação da Política Nacional de Mobilidade Urbana, instituída pela Lei No 12.587/2012, bem como a Lei No 10.257/2001 (Estatuto da Cidade) e o Decreto No 5.296/2004. Nele propõe ainda a criação de um Sistema Único de Mobilidade Urbana semelhante ao Sistema Único de Saúde (SUS), que contemple principalmente linhas de financiamento, dentre outras medidas.

Para Lima et al. (2020) do Centro de Estudos de Regulação e Infraestrutura da FGV (CERI), usuários, operadores e poder público deverão definir estratégias para evitar a propagação do vírus, manter a operação adequada do serviço e garantir a viabilidade financeira das empresas. Para usuários: evitar deslocamentos desnecessários e se necessário ajustar a hora de utilização do transporte público; higienizar as mãos e utilizar máscaras de proteção facial; e se possível realizar caminhadas ou utilizar bicicleta. Para operadores: tomar decisões para proteger passageiros e trabalhadores, minimizar os impactos para a organização e ainda fornecer um nível de serviço apropriado para a situação, enfrentando os desafios de prevenir a propagação da doença, manter os serviços, fazer um gerenciamento eficaz da comunicação e a manutenção do equilíbrio econômico e financeiro. Ao poder público cabe a oferta de outros modos mais seguros como a expansão das ciclovias e garantir a sustentabilidade financeira da operação durante a crise.

A Associação Nacional de Transportadores de Passageiros sobre Trilhos registra queda de demanda de $82 \%$ na demanda de metrôs e trens logo após o inicio da pandemia 
(ANPTrilhos, 2020). A diminuição das receitas em função da queda no número de passageiros, somada aos custos extras decorrentes do aumento do rigor da higienização e compra de equipamentos de proteção para os funcionários, coloca em risco a continuidade dos serviços. Caso não haja socorro ao setor de ônibus, estima-se que as empresas não conseguirão pagar salários e manter a frota adequada em operação (NTU, 2020). Dessa forma, a manutenção dos serviços de transporte enfrenta desafios não apenas agora, mas também após a flexibilização do isolamento horizontal.

O documento da NTU, FABUS, ANFAVEA, Forum dos Secretários e Dirigentes da Mobilidade Urbana e ANTP "Como ter um Transporte Público Eficiente, Barato e com Qualidade na sua cidade" inicia afirmando que o transporte público é uma atividade essencial e é, desde 2015, um direito social constitucional, ao lado da saúde, educação e segurança. A pandemia da Covid-19 mostrou a importância de um bom serviço de transporte público, e tornou evidentes as falhas e limitações atuais. Os prefeitos que assumiram este ano estão enfrentando os enormes impactos causados pela pandemia em quase todos os setores da sociedade, com orçamentos reduzidos, lento reaquecimento da economia e queda da renda da população. Para tanto as novas administrações deveriam guiar-se pelos conceitos de: Transparência (proporcionar informações ilimitadas); Novos Modelos de Contratação (por tarifa de remuneração à operadora pelo serviço e outra para os usuários com subsídios); Infraestrutura (priorização do transporte público); Custeio (modelo de financiamento baseado em recursos públicos e de beneficiários indiretos); Qualidade; e Ações Emergenciais (aportar recursos emergenciais para cobertura do déficit, repactuar os contratos vigentes, adequar a lotação dos veículos e terminais, prioridade na via, melhorar o funcionamento dos terminais e escalonar as diversas atividades urbanas (NTU et al., 2020).

Como síntese da literatura revisada, percebe-se que a maioria se baseia em diagnósticos e diretrizes de enfrentamento e os resultados ainda são preliminares, deixando margem para lacunas e incertezas, inclusive da manutenção do paradigma da mobilidade sustentável. As desconfianças com relação ao transporte público poderão se estender para um novo normal, deixando esse serviço apenas para usuários sem alternativas. Como estratégias de enfrentamento, além da redução da ocupação dos veículos, percebe-se a necessidade de financiamentos adicionais para viabilizar a operação do transporte público em déficit. Como consequência da crise a incerteza regulatória deve crescer dando margens a várias tendências, desde a aceleração na direção da mobilidade sustentável com mais mobilidade ativa, até o recrudescimento do uso do automóvel. Os governos passam a desempenhar um papel crucial nessa mediação.

\section{Metodologia}

A base de todas as análises e propostas contidas neste artigo foi extraída de oito seminários realizados entre 21/05 e 27/08/2020, com participação de 43 palestrantes / debatedores convidados de diversas instituições acadêmicas nacionais, latino-americanas e ibéricas, entidades representantes dos setores empresariais dos transportes, gestores públicos de oito capitais brasileiras, representantes de entidades do terceiro setor de usuários de meios de transportes. Na composição dos participantes do Fórum buscou-se reunir atores que representem as diversas percepções sobre a problemática com abrangência geográfica nacional a mais ampla possível, complementada por contribuições e análises de alguns atores com visões externas ao Brasil. No Apêndice A, estão relacionados os oito seminários técnicos que compuseram o Fórum, com detalhamento dos temas discutidos e dos palestrantes/debatedores. 
Para sintetizar, estruturar e hierarquizar problemas, causas e soluções para superar a insustentabilidade do modelo atual de transporte público agravado pelas restrições da pandemia, foram levados em conta instrumentos combinados de análise de sistemas complexos e de planejamento estratégico. Com base nos depoimentos nos seminários, esses métodos vão desde a utilização de técnicas de análises de causas e efeitos para construir diagnósticos preliminares e de análise de Pareto para identificar as questões principais, passando pela revisão sistemática da literatura em textos científicos para buscar elementos teóricos influentes no fenômeno, até a estruturação de ideias e estratégias de superação dos problemas por meio da aplicação do instrumental da Matriz de Marco Lógico. Trata-se, portanto, de metodologia fundamentalmente qualitativa combinando diferentes instrumentos.

Para capturar a essência das discussões abertas e não estruturadas de apresentadores e debatedores no Fórum, gravações de áudios transformadas por processamento de linguagem natural em textos foram organizadas em ideias estruturadas, por meio da identificação de tópicos relevantes nos conteúdos. Essas ideias reveladas nos debates foram organizadas em tópicos que se relacionam por interpretação da leitura dos textos, a problemas, soluções e barreiras a superar a partir da problemática estudada. Ideias-força ou significados, transformados pela frequência de citação em matrizes numéricas, foram extraídos das discussões e apresentados em forma de nuvens de palavras por meio de processamento pelo software Orange 3.16. Com base nesses significados revelados e organizados foram aplicadas técnicas de análise de causa e efeito e de planejamento estratégico para superar os desafios para uma mobilidade sustentável e resiliente em um contexto de pandemia.

O diagrama de Espinha de Peixe concebido por Ishikawa em 1960, inicialmente como ferramenta de análise de qualidade de um produto ou serviço, objetiva sugerir relações causais de um problema complexo identificado de forma logicamente organizada e em detalhes crescentes (Ilie e Ciocoiu, 2010). Além das análises clássicas de qualidade na indústria, o instrumento proposto por Ishikawa tem sido utilizado em aplicações em várias áreas, entre elas o serviço público. Slameto (2016) aplicou o diagrama para apoiar um programa de qualidade das escolas na Indonésia, e por meio do conhecimento das causas raízes dos problemas, identificar estratégias para melhoria dos processos. Moufad e Jawab (2017) aplicaram a técnica para destacar das causas dos problemas de transportes públicos em Fez - Marrocos, os aspectos sociais, econômicos, institucionais e ambientais. Cheng et al. (2019) aplicaram um diagrama de Espinha de Peixe para classificar causas de acidentes aéreos no Canadá.

Para a ASQ (2021), na aplicação da técnica, parte-se de um problema principal identificado por consenso, representado por um efeito adverso e coloca-o como o centro das atenções de análise na ponta de uma seta. A partir desse problema focado, busca-se por brainstorming, identificar as categorias principais das causas, que se transformam em ramos na direção da seta principal. Entenda-se categoria como um conjunto de causas com raízes comuns. Essas causas são respostas à questão de porque o problema acontece. Depois para cada categoria de causa, se faz a mesma pergunta e se respondem com as sub-causas, aprofundando as questões. Assim, constrói-se o diagrama. No caso deste artigo, as respostas que conduziram ao problema principal (efeito) e o grupo de categorias de causas e sub-causas foram extraídas da interpretação e estruturação em ideias-força dos depoimentos e debates (Figura 2). 


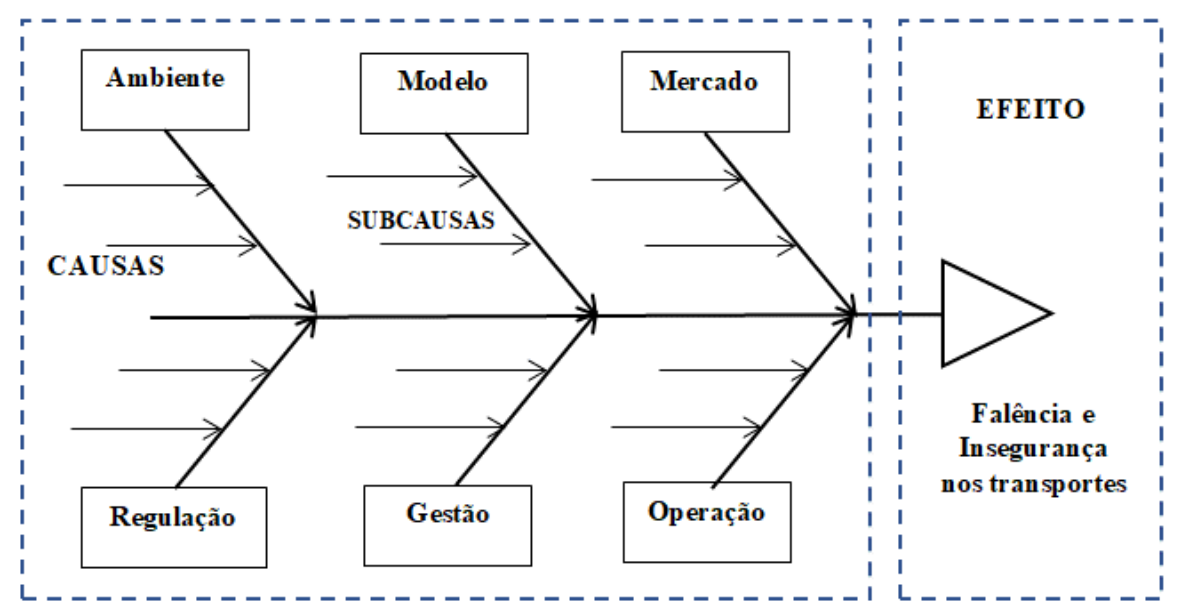

Figura 2. Esquema do diagrama de Ishikawa aplicado à situação estudada. Fonte: Elaboração própria.

A partir das análises de causas e efeito extraídas do diagrama, podem-se interpretar em nível estratégico, táctico e operacional, quais categorias de causas e que tipos de ações podem ser empreendidos em cada nível, para elaborar uma política ou um projeto para enfrentar o problema.

O efeito principal do problema analisado - a possibilidade de falência dos sistemas de transportes públicos brasileiros e a exposição ao risco de contágio dos usuários cativos do sistema - passa a ser o foco do objetivo principal dos estudos resumidos neste artigo. Assim, adotou-se a metodologia de planejamento estratégico denominada Matriz de Marco Lógico (MML), largamente utilizada a partir dos anos 1970 por organismos multilaterais de financiamento do desenvolvimento, como o Banco Mundial.

A MML pode prover uma eficiente observação sobre objetivos de projetos ou políticas, fortalecendo a atenção para possíveis justificativas em nível superior, condições externas e necessidade de informação para monitoramento e avaliação. Como aplicação em transportes, Benitez (2016) realizou um estudo dos problemas de implementação do Transantiago utilizando uma análise ex-post pela MML, comparando as condições prévias com as decisões tomadas, buscando identificar em que pontos ou áreas as questões em aberto no planejamento resultaram nas dificuldades enfrentadas. No estudo identificou-se como causa principal o não cumprimento dos pressupostos de uma ação de gestão pública e comunicação eficazes que resultaram em expectativas do público frustradas devido a problemas nos transbordos. Na Itália, Russo e Rindone (2008) aplicaram a MML para desenvolver um plano de emergência para evacuação de rodovias em situações de risco, considerando uma lógica de conexão entre causas e efeitos.

Para Gasper (2000) e Couillard (2009), a MML apresenta: i) uma estrutura hierárquica de objetivos que convergem para um objetivo superior; ii) um conjunto de indicadores de resultados mensuráveis e com metas no tempo; iii) fontes de informações verificáveis e válidas do atingimento dos objetivos; iv) pressupostos sobre os fatores relevantes. A seguir na Figura 3 está apresentada a estrutura de uma matriz teórica, que é antecedida pelas árvores de problemas e de objetivos, segundo o Manual da Swiss Agency for Development and Cooperation (SDC): 


\begin{tabular}{|c|c|c|c|c|c|}
\hline & & A & B & C & $D$ \\
\hline $\begin{array}{l}\text { Árvore de } \\
\text { Problemas }\end{array}$ & $\begin{array}{l}\text { Árvore De } \\
\text { Objetivos }\end{array}$ & $\begin{array}{l}\text { Hierarquia de } \\
\text { Objetivos }\end{array}$ & Indicadores & $\begin{array}{l}\text { Meios de } \\
\text { verificaçãa }\end{array}$ & $\begin{array}{l}\text { Fatores } \\
\text { externos (pré- } \\
\text { requisitos) }\end{array}$ \\
\hline Efeitos & Fins & $\begin{array}{c}\text { Impacto- } \\
\text { Objetivo Geral }\end{array}$ & $\begin{array}{l}\text { Indicadores de } \\
\text { impacto }\end{array}$ & $\begin{array}{l}\text { Fontes de } \\
\text { informação }\end{array}$ & Pré-requisitos \\
\hline $\begin{array}{l}\text { Problema } \\
\text { Central }\end{array}$ & $\begin{array}{l}\text { Situação } \\
\text { Desejada }\end{array}$ & $\begin{array}{l}\text { Objetivos do } \\
\text { Projeto }\end{array}$ & $\begin{array}{l}\text { Indicadores de } \\
\text { efetividade }\end{array}$ & $\begin{array}{l}\text { Fontes de } \\
\text { informação }\end{array}$ & Pré-requisitos \\
\hline Causas & Meios & Resultados & $\begin{array}{l}\text { Indicadores de } \\
\text { eficácia }\end{array}$ & $\begin{array}{l}\text { Fontes de } \\
\text { informação }\end{array}$ & Pré-requisitos \\
\hline & & Atividades & $\begin{array}{l}\text { Indicadores de } \\
\text { eficiência }\end{array}$ & & Pré-requisitos \\
\hline
\end{tabular}

Figura 3. Árvore de Problema e Objetivo e a Matriz do Marco Lógico. Fonte: SDC.

A lógica da intervenção pela MML, como esquematizada na Figura 4, fundamenta-se num fluxo de entradas que vai contribuir para o objetivo superior ou impacto, com etapas intermediárias de atividades, que geram produtos e que produzem resultados parciais. Assim, se as atividades em nível básico ou de entrada forem realizadas e os pressupostos atendidos, então os resultados buscados também serão atendidos. Assim em lógica cruzada sequenciada, as atividades, produtos e resultados devem contribuir para o objetivo superior de projeto ou das mudanças pretendidas.

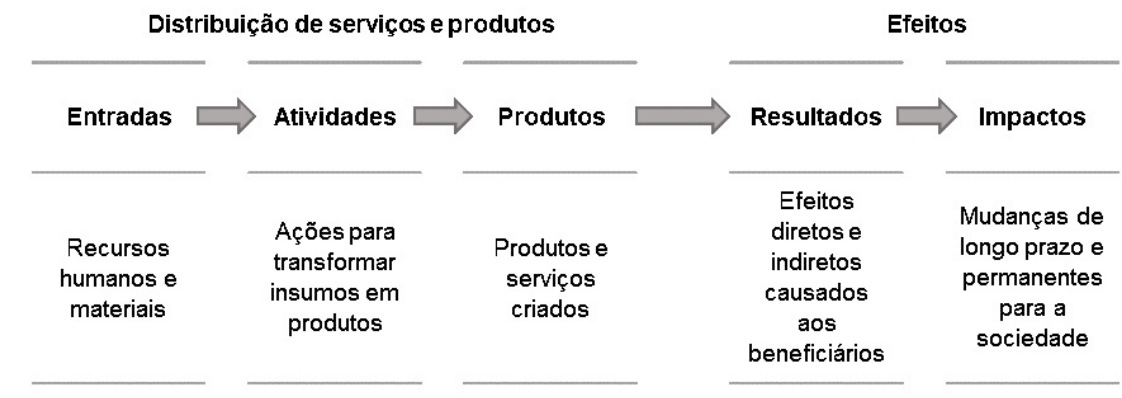

Figura 4. A lógica da intervenção. Fonte: SDC.

Em síntese, esses passos metodológicos buscam extrair das ideias discutidas no conjunto de seminários, ações nos níveis estratégicos, táticos e operacionais para apontar saídas para a crise agravada nos transportes públicos nas cidades brasileiras. Imaginase com a exploração dessa estrutura metodológica demonstrar propostas que sejam capazes de superar os problemas atuando sobre suas causas. Ao mesmo tempo, busca-se superar barreiras políticas, institucionais, tecnológicas, legais e financeiras (pressupostos) para assegurar a efetividade da política.

\section{Resultados e discussões}

Como exposto na apresentação da metodologia, as propostas estratégicas para o problema dos transportes públicos urbanos no contexto da pandemia, foram extraídas de ideias discutidas durante os oito seminários do Fórum. Espera-se pela análise da participação de painéis de especialistas com foco nos problemas de mobilidade das cidades brasileiras, extrair e estruturar ideias que possam, superados problemas estruturais sérios de planejamento, financiamento e gestão dos transportes, apontar diretrizes: (i) no curto prazo para garantir à população transportes seguros e sustentáveis, 
minimizando os riscos de contágios da Covid-19; e (ii) no médio prazo para propor modelos de transporte público no Brasil reformados em suas estruturas, tornandoos sustentáveis e resilientes a crises. A Figura 5 apresenta inicialmente os problemas e barreiras a superar e suas ideias-força expressas a partir do Fórum em nuvens de palavras, onde o tamanho das palavras indica sua frequência de citação.

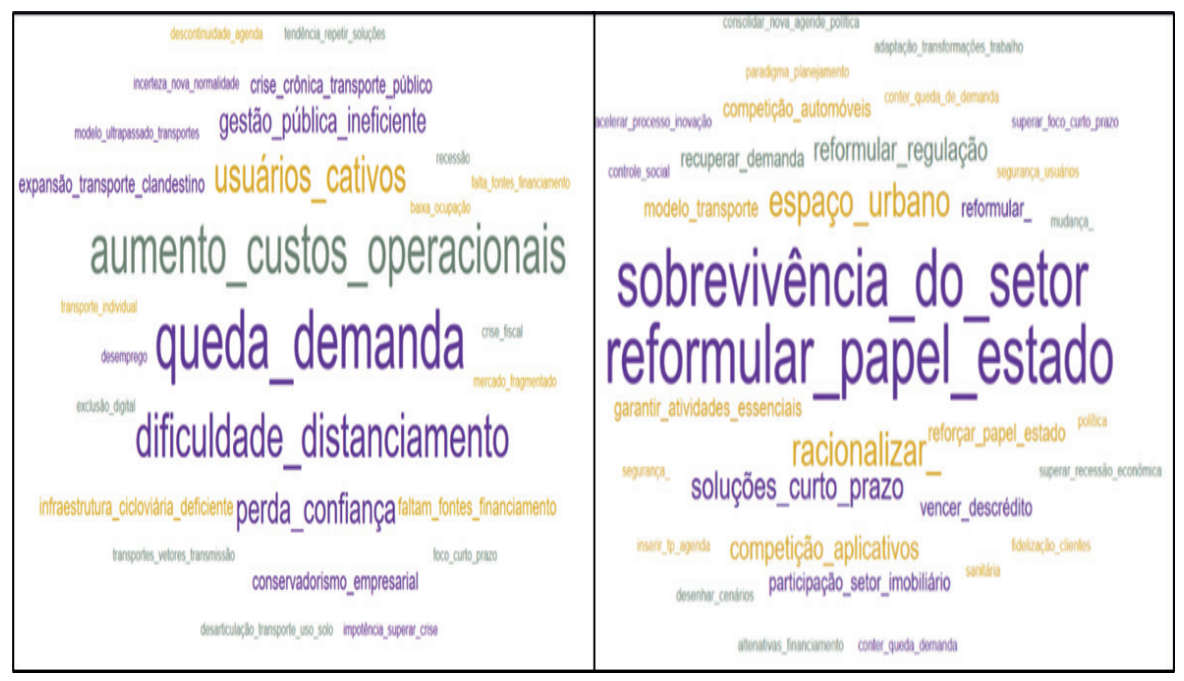

Figura 5. Nuvens de palavras de problemas e barreiras a superar no contexto da pandemia da Covid-19. Fonte: Elaboração própria.

Aplicando-se uma análise de Pareto ao conjunto de ideias, verifica-se que as causas seguintes respondem por $80 \%$ das consequências do problema, são elas: i) queda da demanda; ii) desequilíbrio econômico financeiro do transporte público; iii) modelo de financiamento ultrapassado baseado quase exclusivamente na tarifa paga pelos usuários, sem subsídios governamentais, nem privados; iv) gestão pública ineficiente sem pessoal técnico preparado, nem disponibilidade de métodos inovadores de controle da demanda e da oferta e com grande dependência dos operadores, tanto na gestão dos dados operacionais, quanto na receita financeira do sistema; v) congestionamento das vias afetando o transporte público; vi) investimento insuficiente no sistema de transporte público; vii) recessão econômica agravada pela pandemia, aumenta de forma imensa o desemprego e a exclusão social, o que por sua vez diminui a demanda por transporte público; e viii) usuários cativos são os únicos que permanecem utilizando o serviço de transporte público, devido a necessidade de se deslocar à falta de outra opção de deslocamento.

Também aplicando a análise de Pareto sobre o conjunto de desafios discutidos no Fórum, destacam-se os seguintes que representam cerca de $80 \%$ do esforço demandado para superá-los. Em síntese, é estratégico atuar prioritariamente sobre os seguintes desafios: i) mudar a forma de planejar o transporte público e sua estrutura de financiamento; ii) reformular o papel do Estado no que tange a questão do transporte público; iii) garantir a sobrevivência do setor de transporte público - que já vinha tendo uma queda significativa da demanda e com a pandemia a queda da demanda acentuou-se chegando a $75 \%$ no caso da Região Metropolitana do Recife (RMR), tendo custos acrescidos devido as medidas sanitárias e mantendo oferta no dobro da demanda. Isto produz déficits que podem levar as operadoras à falência; iv) concorrência com os automóveis, que têm recebido toda a prioridade do poder público, somando-se a concorrência com aplicativos sem regulamentação; e v) necessidade de consolidar uma nova agenda política que ponha em prática a Lei de Mobilidade, estabelecendo uma inversão da prioridade nas ações 
do Poder Público, que passa incentivar a caminhada, o uso da bicicleta e do transporte público e implementando ações restritivas ao uso dos automóveis.

Estes problemas são discutidos a seguir sobre duas óticas, a primeira das ações imediatas que devem ser tomadas a fim de enfrentar os desafios que a pandemia trouxe para o setor de transporte público e a segunda tratará das questões de médio e longo prazo que procurarão propor medidas estratégicas para retirar o transporte público da situação extremamente precária que já vinha vivenciando e que se agravou fortemente. Juntando problemas e desafios, as ideias apresentadas no Fórum apontam para a seguinte hierarquia de soluções que requerem soluções imediatas (Figura 6):

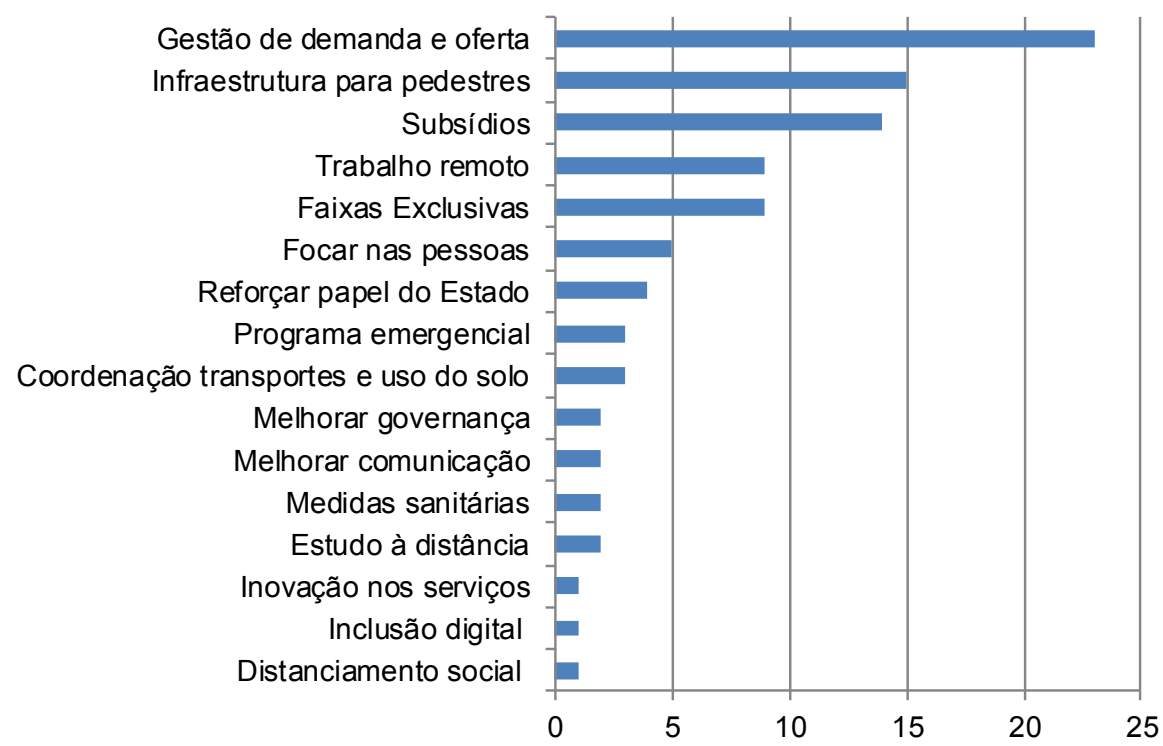

Figura 6. Ações imediatas propostas. Fonte: Elaboração própria.

Como pressupostos para esses objetivos, aponta-se preliminarmente, no curto prazo a tomada de decisão política nas três esferas de poder no Brasil para o financiamento do transporte público (MDT, 2020), sua inserção na agenda da saúde pública e novos modos de regulação dos serviços de transporte por ônibus. O pressuposto essencial para o alcance dos objetivos no médio prazo é a inserção no pacto federativo da agenda do transporte público (ambiente externo), o que significa a busca de financiamento compartilhado entre os atores, a elaboração de novas regulamentações locais e a implementação de novas formas de concessões para os serviços de transporte por ônibus, bicicletas, motos, modos ferroviários, transporte sob demanda (usando aplicativos).

A ligação entre o diagrama de causa e efeito e a MML, passa pela formulação de uma árvore de problemas e por uma árvore de objetivos, conforme descrito na metodologia. A árvore de problemas parte da base das causas apontadas no diagrama de Espinha de Peixe, que são categorizadas em ambiente externo (Covid, pobreza, crise do Estado e suas consequências), regulação (financiamento e disponibilidade de dados dos operadores privados à gestão insuficiente), modelo (contratos e redes inflexíveis e desequilíbrio financeiro) e gestão pública (deficiências de gestão, de planejamento e de capacitação de pessoal). Essas causas vão ser combatidas pelos meios que aparecem na base da árvore de objetivos, que representam as ações ou soluções propostas parte delas apresentadas na Figura 7. 
Análises de causa e efeitos - Diagrama de Ishikawa

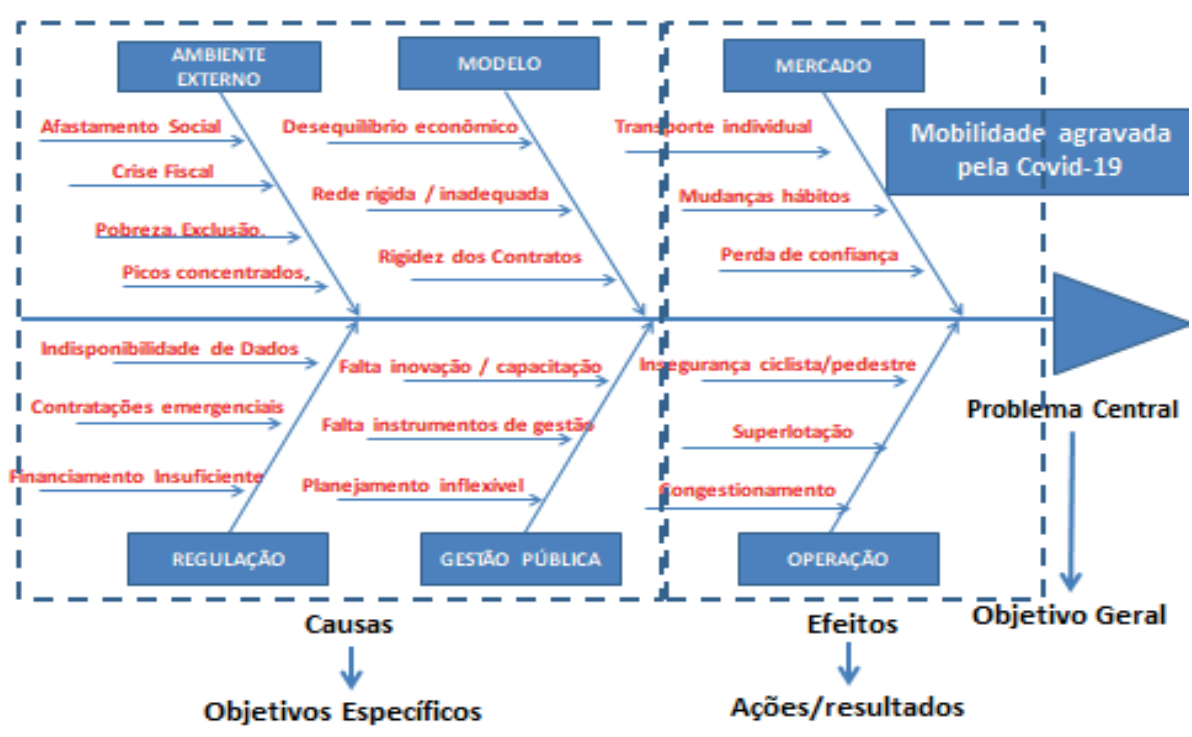

Figura 7. Análises de causas e efeitos - Diagrama de Ishikawa. Fonte: Elaboração própria.

Os efeitos na parte superior da árvore de problemas foram também extraídos das categorias do diagrama: mercado (perda de confiança no transporte público, mudanças de hábitos dos usuários) e operação (insegurança, superlotação e congestionamentos). Essas categorias de efeitos vão apontar os objetivos do projeto ou da política. Os níveis de intervenção para atuação sobre os problemas são divididos em estratégico, tático e operacional, e suas associações com causas e efeitos estão apresentados na Figura 8:

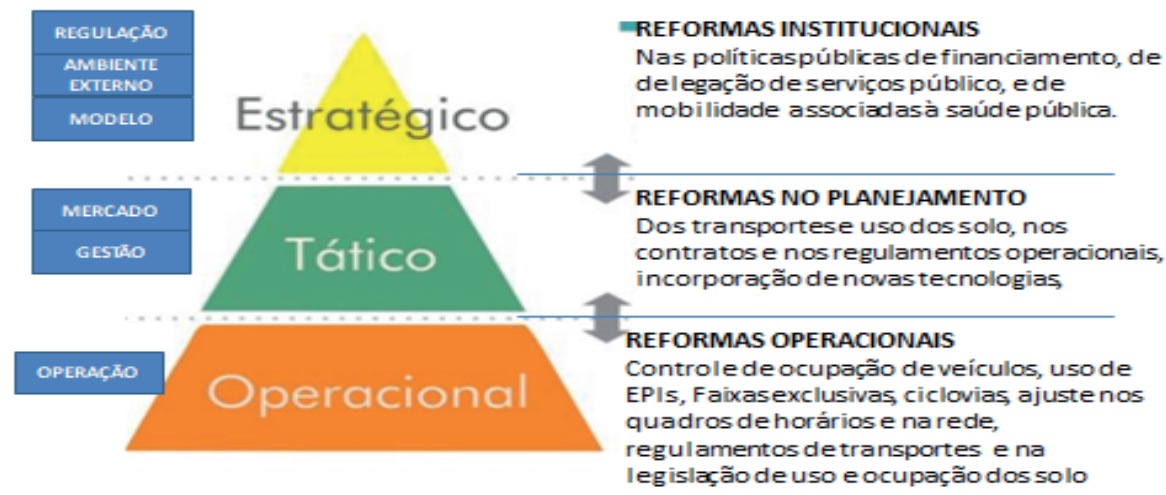

Figura 8. Níveis de intervenção para enfrentar os problemas. Fonte: Elaboração própria.

A seguir está apresentada na Quadro 1 a estruturação da Matriz do Marco Lógico elaborada com as colunas de objetivos, indicadores, ponto de verificação e pressupostos e a linhas de Objetivo Superior, Objetivos Específicos, Resultados e atividades. Como esta matriz completa é extensa, a apresentação de cada um dos níveis é realizada separadamente a seguir. A matriz completa foi validada nesse formato pelos participantes do Fórum no $7^{\circ}$ e $8^{\circ}$ seminários. 
O desafio da sustentabilidade nos transportes públicos...

Quadro 1. Matriz do Marco Lógico - Estruturação completa. Fonte: Elaboração própria.

\begin{tabular}{|l|l|l|l|l|}
\hline Nível Estratégico & Objetivo Superior & $\begin{array}{l}\text { Indicadores de impacto } \\
\text { da política }\end{array}$ & Fonte e Verificação & $\begin{array}{l}\text { Pressupostos do } \\
\text { objetivo superior }\end{array}$ \\
\hline $\begin{array}{l}\text { Nível Estratégico e } \\
\text { Tático }\end{array}$ & Objetivos Específicos & $\begin{array}{l}\text { Indicadores de } \\
\text { efetividade das } \\
\text { estratégias parciais }\end{array}$ & Fonte De Verificação & $\begin{array}{l}\text { Pressupostos dos } \\
\text { objetivos específicos }\end{array}$ \\
\hline $\begin{array}{l}\text { Nível Tático e } \\
\text { Operacional }\end{array}$ & Resultados & $\begin{array}{l}\text { Indicadores de } \\
\text { resultados (eficácia) } \\
\text { das ações }\end{array}$ & Fonte De Verificação & $\begin{array}{l}\text { Pressupostos dos } \\
\text { resultados das ações. }\end{array}$ \\
\hline Nível Operacional & Atividades & $\begin{array}{l}\text { Indicadores de } \\
\text { eficiência das ações }\end{array}$ & Fonte De Verificação & Pressupostos das ações \\
\hline
\end{tabular}

No nível Estratégico ou da ação da política nos escalões superiores e no legislativo, situa-se o objetivo superior que foca nas reformas estruturais no financiamento, na regulação de delegação e nas políticas associadas de transportes e saúde pública. Estabelece-se assim, a primeira linha da MML, apresentada na Quadro 2 considerando por simplificação, objetivo, indicadores e pressupostos.

Quadro 2. Matriz do Marco Lógico - Nível Estratégico. Fonte: Elaboração própria.

\begin{tabular}{|c|c|c|c|}
\hline Objetivo Superior & Indicadores & Fonte De Verificação & Pressupostos \\
\hline \multirow{4}{*}{$\begin{array}{l}\text { À população são } \\
\text { assegurados meios de } \\
\text { transportes seguros } \\
\text { e sustentáveis para } \\
\text { minimizar riscos de } \\
\text { contágio da Covid-19. }\end{array}$} & $\begin{array}{l}\text { Redução significativa } \\
\text { nos casos confirmados } \\
\text { e/ou nas taxas } \\
\text { de mortalidade/ } \\
\text { letalidade. }\end{array}$ & $\begin{array}{l}\text { Pesquisas da } \\
\text { Secretaria da Saúde }\end{array}$ & $\begin{array}{l}\text { Decisão política nas } \\
\text { três esferas de poder e } \\
\text { no legislativo }\end{array}$ \\
\hline & $\begin{array}{l}\text { Estabilidade abaixo } \\
\text { de o,8 da taxa de } \\
\text { transmissibilidade. }\end{array}$ & $\begin{array}{l}\text { Pesquisas da } \\
\text { Secretaria da Saúde }\end{array}$ & $\begin{array}{l}\text { Financiamento público } \\
\text { emergencial. }\end{array}$ \\
\hline & $\begin{array}{l}\text { Rastreabilidade de } \\
\text { casos nos transportes } \\
\text { (\% passageiros c/ } \\
\text { febre) }\end{array}$ & $\begin{array}{l}\text { Medição de } \\
\text { temperatura à } \\
\text { distância }\end{array}$ & $\begin{array}{l}\text { O transporte público } \\
\text { no contexto da } \\
\text { pandemia se insere } \\
\text { nas políticas de } \\
\text { financiamento da } \\
\text { saúde }\end{array}$ \\
\hline & $\begin{array}{l}\text { Índice de } \\
\text { cumprimento de } \\
\text { viagens seguras. }\end{array}$ & $\begin{array}{l}\text { Monitoramento } \\
\text { do órgão gestor / } \\
\text { Pesquisas de opinião. }\end{array}$ & $\begin{array}{l}\text { Reforma na legislação } \\
\text { e nos regulamentos de } \\
\text { contração e gestão dos } \\
\text { transportes }\end{array}$ \\
\hline
\end{tabular}

Nos níveis estratégico e tático, situam-se ações focadas nas reformas estruturais e suas extensões ao nível do planejamento. Esses níveis de intervenções ainda estão sob a responsabilidade dos decisores políticos diretos apoiados por seu staff superior, assim apresentam-se em sequência na Quadro 3, os objetivos específicos, seus indicadores e pressupostos. 
O desafio da sustentabilidade nos transportes públicos...

Quadro 3. Matriz do Marco Lógico - Nível Estratégico e Tático. Fonte: Elaboração própria.

\begin{tabular}{|l|l|l|l|}
\hline Objetivos Específicos & Indicadores & Fonte De Verificação & Pressupostos \\
\hline $\begin{array}{l}\text { 1. Reduzir riscos } \\
\text { de contágio por } \\
\text { proximidade nos } \\
\text { ônibus, terminais e } \\
\text { paradas. }\end{array}$ & $\begin{array}{l}\text { 1. Número de } \\
\text { passageiros por } \\
\text { veículo. }\end{array}$ & $\begin{array}{l}\text { 1. Fiscalização e } \\
\text { monitoramento } \\
\text { eletrônico }\end{array}$ & $\begin{array}{l}\text { 1. Exigência de } \\
\text { regulamentação } \\
\text { da saúde para os } \\
\text { operadores e gestores } \\
\text { de transportes }\end{array}$ \\
\hline $\begin{array}{l}\text { 2. Reduzir tempo de } \\
\text { exposição ao risco. }\end{array}$ & $\begin{array}{l}\text { 2. Velocidade } \\
\text { operacional dos } \\
\text { ônibus }\end{array}$ & $\begin{array}{l}\text { 2. Fiscalização } \\
\text { amostral nos } \\
\text { registros de viagens. }\end{array}$ & $\begin{array}{l}\text { 2. Decisão política } \\
\text { de expandir faixas } \\
\text { exclusivas para } \\
\text { transportes públicos. }\end{array}$ \\
\hline $\begin{array}{l}\text { 3. Ajustar a oferta } \\
\text { à demanda de } \\
\text { segurança. }\end{array}$ & $\begin{array}{l}\text { 3. Tempo de viagem/ } \\
\text { tempo de espera. }\end{array}$ & $\begin{array}{l}\text { 3. Monitoramento } \\
\text { do órgão gestor / } \\
\text { Pesquisas de opinião. }\end{array}$ & $\begin{array}{l}\text { 3. Decisão política de } \\
\text { reforçar financiamento } \\
\text { ao transporte. }\end{array}$ \\
\hline $\begin{array}{l}\text { 4. Garantir condições } \\
\text { para transportes } \\
\text { ativos. }\end{array}$ & $\begin{array}{l}\text { 4. Quilometragem de } \\
\text { ciclovias operando. }\end{array}$ & $\begin{array}{l}\text { 4. Verificação em } \\
\text { campo / pesquisas de } \\
\text { opinião. }\end{array}$ & $\begin{array}{l}\text { 4. Decisão política de } \\
\text { investir em ciclofaixas } \\
\text { e calçadas. }\end{array}$ \\
\hline $\begin{array}{l}\text { 5. Ajustar a demanda à } \\
\text { capacidade. }\end{array}$ & $\begin{array}{l}\text { 5. Volumes nos picos } \\
\text { por linhas. }\end{array}$ & 5. Pesquisa de campo & $\begin{array}{l}\text { 5. Disponibilidade } \\
\text { de dados e decisão } \\
\text { administrativa e } \\
\text { política. }\end{array}$ \\
\hline $\begin{array}{l}\text { 6. Disponibilizar } \\
\text { informações e } \\
\text { comunicações sobre } \\
\text { transportes eficientes. }\end{array}$ & $\begin{array}{l}\text { 6. Acesso à informação } \\
\text { em tempo real. }\end{array}$ & $\begin{array}{l}\text { 6. Testes semanais no } \\
\text { software }\end{array}$ & $\begin{array}{l}\text { 6. Decisão política e } \\
\text { administrativa. }\end{array}$ \\
\hline
\end{tabular}

Nos níveis tático e operacional, situam-se ações planejadas por níveis intermediários administrativos e por operadores e executores diretos, daí incluem atividades que buscam resultados para alimentar os objetivos específicos. Em termos de atividades, indicadores e pressupostos a matriz apresenta as seguintes propostas, apresentadas na Quadro 4.

Quadro 4. Matriz do Marco Lógico - Nível Tático e Operacional. Fonte: Elaboração própria.

\begin{tabular}{|l|l|l|l|}
\hline Resultados & Indicadores & Fonte De Verificação & Pressupostos \\
\hline $\begin{array}{l}\text { 1. Ônibus, trens e } \\
\text { metrô operam com } \\
\text { limitação na taxa de } \\
\text { ocupação. }\end{array}$ & $\begin{array}{l}\text { 1. Veículos de } \\
\text { transporte público } \\
\text { devem circular apenas } \\
\text { com passageiros } \\
\text { sentados. }\end{array}$ & $\begin{array}{l}\text { 1. Fiscalização } \\
\text { amostral em campo } \\
\text { pelo órgão gestor. }\end{array}$ & $\begin{array}{l}\text { 1. Implantação } \\
\text { de sensores } \\
\text { para contagem } \\
\text { de passageiros, } \\
\text { integrados à central de } \\
\text { controle e a sistema } \\
\text { de informação aos } \\
\text { usuários. }\end{array}$ \\
\hline $\begin{array}{l}\text { 2. Veículos e } \\
\text { instalações } \\
\text { higienizados e } \\
\text { desinfectados. }\end{array}$ & $\begin{array}{l}\text { 2. Todas as viagens } \\
\text { serão iniciadas com } \\
\text { veículos higienizados } \\
\text { e desinfetados. }\end{array}$ & $\begin{array}{l}\text { 2.Verificação amostral } \\
\text { nos registros do órgão } \\
\text { gestor }\end{array}$ & $\begin{array}{l}\text { 2. Disponibilização de } \\
\text { pessoal de limpeza } \\
\text { e de fiscalização em } \\
\text { todos os terminais das } \\
\text { linhas. }\end{array}$ \\
\hline $\begin{array}{l}\text { 3. Velocidade } \\
\text { operacional dos } \\
\text { ônibus elevada. }\end{array}$ & $\begin{array}{l}\text { 3. Elevação da } \\
\text { velocidade média } \\
\text { operacional em 5o\% } \\
\text { em relação à média } \\
\text { anterior. }\end{array}$ & $\begin{array}{l}\text { 3.Verificação amostral } \\
\text { nos registros do órgão } \\
\text { gestor }\end{array}$ & $\begin{array}{l}\text { 3. Disponibilidade de } \\
\text { projetos executivos } \\
\text { de sinalização dos } \\
\text { corredores. Sistema } \\
\text { de monitoramento das } \\
\text { faixas exclusivas por } \\
\text { câmeras. }\end{array}$ \\
\hline
\end{tabular}




\begin{tabular}{|c|c|c|c|}
\hline Resultados & Indicadores & Fonte De Verificação & Pressupostos \\
\hline $\begin{array}{l}\text { 4. Oferta de serviços } \\
\text { ajustada às condições } \\
\text { de operação segura. }\end{array}$ & $\begin{array}{l}\text { 4. Redução do } \\
\text { tempo de espera em } \\
\text { terminais e paradas } \\
\text { para } 5 \text { minutos. }\end{array}$ & $\begin{array}{l}\text { 4. Pesquisa de } \\
\text { campo e/ou de } \\
\text { monitoramento do } \\
\text { tráfego. }\end{array}$ & $\begin{array}{l}\text { 4. Disponibilidade } \\
\text { de base de dados, } \\
\text { de softwares e de } \\
\text { pessoal treinado } \\
\text { para modelagem da } \\
\text { demanda em tempo } \\
\text { real. }\end{array}$ \\
\hline $\begin{array}{l}\text { 5. Alternativas seguras } \\
\text { de modalidades ativas } \\
\text { disponibilizadas em } \\
\text { toda a cidade. }\end{array}$ & $\begin{array}{l}\text { 5. Aumento da } \\
\text { utilização de bicicletas } \\
\text { para } 10 \text { a } 15 \% \text { dos } \\
\text { deslocamentos. }\end{array}$ & $\begin{array}{l}\text { 5. Contagens de } \\
\text { campo e comparação } \\
\text { com dados existentes } \\
\text { anteriores. }\end{array}$ & $\begin{array}{l}\text { 5. Disponibilização de } \\
\text { projetos executivos } \\
\text { de operação e } \\
\text { sinalização de } \\
\text { ciclovias, ciclofaixas e } \\
\text { ciclorotas e de pessoal } \\
\text { ou instrumento de } \\
\text { fiscalização para evitar } \\
\text { invasão por veículos } \\
\text { motorizados. }\end{array}$ \\
\hline $\begin{array}{l}\text { 6. Achatamento dos } \\
\text { picos de demanda. }\end{array}$ & $\begin{array}{l}\text { 6. Ajuste da demanda } \\
\text { horária para que não } \\
\text { ultrapasse } 7 \% \text { da } \\
\text { demanda diária. }\end{array}$ & $\begin{array}{l}\text { 6. Monitoramento da } \\
\text { operação }\end{array}$ & $\begin{array}{l}\text { 6. Negociações } \\
\text { fechadas com setores } \\
\text { de economia para } \\
\text { realinhar horários de } \\
\text { trabalho, estudo e de } \\
\text { funcionamento de } \\
\text { serviços. }\end{array}$ \\
\hline $\begin{array}{l}\text { 7. Passageiros } \\
\text { informados sobre } \\
\text { alternativas } \\
\text { disponíveis e nível de } \\
\text { demanda na rede. }\end{array}$ & $\begin{array}{l}\text { 7. Obtenção de } \\
\text { informações via app } \\
\text { sobre a demanda e } \\
\text { oferta em tempo real. }\end{array}$ & $\begin{array}{l}\text { 7. Entrevistas } \\
\text { amostrais com } \\
\text { usuários }\end{array}$ & $\begin{array}{l}\text { 7. Disponibilidade } \\
\text { de tecnologias, } \\
\text { dados e de um } \\
\text { projeto de aplicativo } \\
\text { desenvolvido e } \\
\text { testado. }\end{array}$ \\
\hline
\end{tabular}

No nível operacional ou de execução das tarefas planejadas vêm as atividades básicas com respectivos indicadores apresentados na Quadro 5.

Quadro 5. Matriz do Marco Lógico - Nível Operacional. Fonte: Elaboração própria.

\begin{tabular}{|l|l|l|l|}
\hline Atividades & Indicadores & Fonte De Verificação & Pressupostos \\
\hline $\begin{array}{l}\text { 1. Controlar ocupação } \\
\text { de passageiros nos } \\
\text { ônibus e metrô } \\
\text { em espaços com } \\
\text { ventilação natural e } \\
\text { renovada. }\end{array}$ & $\begin{array}{l}\text { 1. 90\% das viagens } \\
\text { devem ser realizadas } \\
\text { dentro dos limites } \\
\text { estabelecidos por } \\
\text { portarias. }\end{array}$ & $\begin{array}{l}\text { 1. Fiscalização } \\
\text { amostral no trajeto. }\end{array}$ & $\begin{array}{l}\text { 1. Cooperação com a } \\
\text { imprensa, ouvidoria e } \\
\text { as associações civis. }\end{array}$ \\
\hline $\begin{array}{l}\text { 2. Higienizar veículos, } \\
\text { abrigos e terminais. }\end{array}$ & $\begin{array}{l}\text { 2. em 90\% das viagens } \\
\text { comprovar ao ser } \\
\text { fiscalizado o registro } \\
\text { de inspeção do veículo } \\
\text { na viagem anterior. }\end{array}$ & $\begin{array}{l}\text { 2. Fiscalização } \\
\text { amostral nos } \\
\text { terminais. }\end{array}$ & $\begin{array}{l}\text { 2. Cooperação com a } \\
\text { imprensa, ouvidoria e } \\
\text { as associações civis. }\end{array}$ \\
\hline $\begin{array}{l}\text { 3. Implantar faixas } \\
\text { exclusivas em todas as } \\
\text { vias com mais de 40 } \\
\text { ônibus/hora. }\end{array}$ & $\begin{array}{l}\text { 3. Aumento de 50\% } \\
\text { na extensão de faixas } \\
\text { exclusivas. }\end{array}$ & $\begin{array}{l}\text { 3. Verificação em } \\
\text { campo. }\end{array}$ & $\begin{array}{l}\text { 3. Monitoramento da } \\
\text { operação das faixas } \\
\text { exclusivas. }\end{array}$ \\
\hline
\end{tabular}




\begin{tabular}{|c|c|c|c|}
\hline Atividades & Indicadores & Fonte De Verificação & Pressupostos \\
\hline $\begin{array}{l}\text { 4. Ajustar rede e } \\
\text { quadro de horários. }\end{array}$ & $\begin{array}{l}\text { 4. Manter constante } \\
\text { a demanda entre } 7 \text { e } \\
10 \text { horas da manhã e } \\
\text { entre } 16 \text { e } 20 \text { h (inferior } \\
\text { a } 7 \% \text { da demanda } \\
\text { diária) e dentro do } \\
\text { limite de ocupação } \\
\text { dos veículos. }\end{array}$ & $\begin{array}{l}\text { 4. Verificação em } \\
\text { campo e pesquisa de } \\
\text { opinião }\end{array}$ & $\begin{array}{l}\text { 4. Cooperação com a } \\
\text { imprensa, ouvidoria e } \\
\text { as associações civis. }\end{array}$ \\
\hline $\begin{array}{l}\text { 5. Implantar planos } \\
\text { cicloviários. }\end{array}$ & $\begin{array}{l}\text { 5. Ampliar em 50\% } \\
\text { as faixas cicláveis em } \\
\text { relação ao período } \\
\text { pré-pandemia. }\end{array}$ & $\begin{array}{l}\text { 5. Verificação em } \\
\text { campo e informações } \\
\text { de associações de } \\
\text { ciclistas. }\end{array}$ & $\begin{array}{l}\text { 5. Monitoramento } \\
\text { do órgão gestor do } \\
\text { trânsito e parceria } \\
\text { com associações de } \\
\text { ciclistas }\end{array}$ \\
\hline $\begin{array}{l}\text { 6. Realinhar horários } \\
\text { de trabalho, estudo, } \\
\text { compras e serviços. }\end{array}$ & $\begin{array}{l}\text { 6. Manter constantes } \\
\text { fluxos nas vias e } \\
\text { nos sistemas de } \\
\text { transportes ao longo } \\
\text { do dia. }\end{array}$ & $\begin{array}{l}\text { 6. Monitoramento o } \\
\text { órgão gestor e dos } \\
\text { representantes dos } \\
\text { operadores. }\end{array}$ & $\begin{array}{l}\text { 6. Negociação } \\
\text { e ajustes pelas } \\
\text { Secretarias de Estado } \\
\text { responsáveis pelo } \\
\text { Desenvolvimento } \\
\text { Urbano, Econômico e } \\
\text { Educação. }\end{array}$ \\
\hline $\begin{array}{l}\text { 7. Implantar sistemas } \\
\text { de comunicação em } \\
\text { tempo real. }\end{array}$ & $\begin{array}{l}\text { 7. Sistema instalado } \\
\text { operando em dois } \\
\text { meses, }\end{array}$ & $\begin{array}{l}\text { 7. Monitoramento do } \\
\text { órgão gestor e dos } \\
\text { representantes dos } \\
\text { operadores. }\end{array}$ & $\begin{array}{l}\text { 7. Cooperação com a } \\
\text { imprensa, ouvidoria e } \\
\text { as associações civis. }\end{array}$ \\
\hline
\end{tabular}

Para testar a consistência transversal da MML, parte-se das atividades e verifica-se se os pressupostos da linha superior foram atendidos para que se chegue aos resultados desejados. Assim, como exemplo, a Ação 3, de implantar faixas exclusivas em todas as vias com mais 40 ônibus/h, só será possível se o pressuposto do resultado de dispor de projetos executivos de operação e sinalização das faixas exclusivas previamente for atendido. Se partirmos da linha de resultados e escolhemos o resultado 6, de achatamento dos picos da demanda, este só se viabiliza se for satisfeito o pressuposto equivalente na linha de objetivos específicos de negociações fechadas com setores de economia para realinhar horários de trabalho, estudo e de funcionamento de serviços. E finalmente, para atingir o objetivo superior, ou o efeito transformador da política, cada um dos objetivos específicos deve ter satisfeitos pressupostos superiores de decisão política, financiamento público emergencial, o transporte público se insere nas políticas de financiamento da saúde e reforma na legislação e nos regulamentos de contração e gestão dos transportes.

Para discutir e validar a MML proposta foram reservados o $7^{\circ} \mathrm{e} 8^{\circ}$ Seminários. No $7^{\circ}$. Seminário, as propostas desenvolvidas a partir da MML foram lidas e discutidas em cada nível (estratégico, táctico e operacional) pelos participantes do Fórum que fizeram recomendações de ajustes, exclusões e complementações. No Seminário Final, junto com as conclusões do Fórum, foi realizada uma nova leitura e discussão da MML revisada com as contribuições do Fórum para validação. Este artigo, portanto, representa o Relatório Final das conclusões e recomendações do Fórum.

\section{Conclusões}

Este artigo partindo da discussão de um contexto de problemas nos transportes públicos e na mobilidade urbana em diversos países e cidades em face da grave crise mundial da pandemia da Covid-19 buscou a visão e a interpretação de um grupo significativo 
de especialistas, para por meio de uma metodologia baseada em um conjunto de instrumentos combinados, sugerir uma estrutura de ações estratégicas articuladas para a mitigação dos efeitos em cidades brasileiras.

A construção deste artigo fundamentou-se, portanto, no conhecimento e expectativas dos participantes do Fórum. Em revisão bibliográfica pelos autores, observou-se que a maioria das medidas tomadas em vários países representa de alguma forma consensos técnicos, embora o nível de implementação e os resultados, naturalmente difiram em razão dos contextos sociais, políticos e econômicos de cada região ou país.

Como síntese dos problemas específicos da realidade brasileira no campo do transporte público já se percebem no horizonte a incerteza da demanda futura, problemas relativos à garantia jurídica dos contratos, tarifas acima da possibilidade de pagamento da população mais pobre e a insustentabilidade financeira da prestação do serviço. Ao mesmo tempo, há exigências cada vez maiores pela sua qualidade a custos menores, além dos novos protocolos sanitários, com redução das taxas de ocupação dos veículos, principalmente nos horários de pico da demanda. Tal crise oportuniza a possibilidade de ampla revisão do modelo vigente, na forma de contratar o serviço, no financiamento das infraestruturas e no seu custeio, e na implementação dos princípios, diretrizes e objetivos da Política Nacional de Mobilidade Urbana - Lei 12.587/2012, uma lei avançada que há anos espera uma oportunidade para sair do papel.

De alguma forma, a inovação de análise contida neste artigo situa-se na adoção de técnicas combinadas de análises de causas e efeitos, normalmente de problemas vinculados à qualidade de algum processo produtivo e de planejamento estratégico de projetos e políticas. Assim, as ações propostas baseiam-se na superação de um conjunto de problemas e seus efeitos, que a partir do alcance de resultados de melhoria baseados em indicadores resultam no atendimento de objetivos específicos ou parciais, que juntos contribuem para a mudança de uma situação problema. No caso estudado o impacto da política é de encontrar meios de operar sistemas de transportes e de mobilidade urbana no contexto de epidemias de forma social e economicamente equilibradas, seguras e sustentáveis.

Em termos de ações emergenciais, neste momento, o poder público deve, juntamente com operadores e a sociedade, buscar alternativas para manter o funcionamento e a viabilidade financeira do sistema. Os usuários devem evitar deslocamentos desnecessários e tomar todas as precauções necessárias para não se contaminarem durante a viagem. Operadores, por sua vez, devem manter o nível de operação adequado agora e proteger passageiros e funcionários. $O$ poder público deve buscar meios financeiros para suprir de recursos adicionais a operação dos serviços em desequilíbrio econômico e tomar essas atitudes de forma ágil. Os cuidados de prevenção à disseminação são especialmente importantes após a flexibilização do isolamento, uma vez que o movimento de pessoas aumentará e ainda não haverá certeza do controle total da situação. Em vista dos desafios colocados, este documento propôs ações a serem empreendidas por cada um dos atores envolvidos - usuários, operadores e poder público - durante esta crise.

As principais estratégias propostas pelo Fórum e resumidas no planejamento estratégico proposto neste artigo situam-se em: i) reduzir riscos de contágios pela redução de passageiros por viagem e nas estações, em deslocamentos mais ágeis para reduzir tempo de exposição; ii) ajustar a oferta à demanda nas novas condições de restrições à ocupação iii) melhorar as condições de infraestruturas para transportes ativos visando aumentar sua atratividade; iv) disponibilizar informações sobre a oferta de transporte, horários e condições de ocupação na rede e nas linhas. 
Como pressuposto fundamental para o sucesso dessas estratégias aponta-se a superação das barreiras de financiamento, de regulação e gestão dos transportes todas a cargo de decisões políticas que devem ser ágeis. Para garantir o direito social constitucional à saúde e ao transporte cabe ao Estado, ao nível da União, estados e municípios, um novo papel de integrador de políticas, superando a separação entre essas duas obrigações para patrocinar políticas integradas e buscando institucionalizar legislações locais que gerem meios adicionais de financiamento com participação de beneficiários indiretos.

Ao fim, espera-se que algumas das medidas tomadas para superar a atual crise permaneçam na fase da normalização, desde que elas promovam um sistema de transportes e de mobilidade urbana resiliente, com menores custos aos usuários e mais confortáveis, confiáveis e sustentáveis.

Agradecimentos: Os autores agradecem ao Conselho Nacional de Desenvolvimento Científico e Tecnológico (CNPq) pelo apoio financeiro e incentivo à realização desta pesquisa. 


\section{Q Bibliografia}

» Almlöf, E., Rubensson, I., Cebecauer, M., y Jenelius, E. (2020). Who Is Still Travelling by Public Transport During COVID-19? Socioeconomic Factors Explaining Travel Behaviour in Stockholm Based on Smart Card Data. Socioeconomic Factors Explaining Travel Behaviour in Stockholm Based on Smart Card Data (September 8, 2020). Disponível em: https://papers.ssrn.com/ sol3/papers.cfm?abstract_id=3689091 (19/03/2021).

» Aloi, A., Alonso, B., Benavente, J., Cordera, R., Echániz, E., González, F., ... y Sañudo, R. (2020). Effects of the COVID-19 lockdown on urban mobility: empirical evidence from the city of Santander (Spain). Sustainability, 12(9), 3870.

"ANPTrilhos (2020). Coronavírus: Metrôs e trens registram queda de demanda de $82 \%$ na última semana. ANP Trilhos. Disponível em https://anptrilhos.org.br/ coronavirus-metros-e-trens-registram-queda-de-demanda-de-82-na-ultimasemana (20/03/2021).

»Araújo, L. R. M. (2019). Demanda Por Transporte Público Em Metrópoles Brasileiras A Partir De Modelos De Regressão Em Painéis Estáticos E Dinâmicos (Dissertação de Mestrado, Universidade Federal De Pernambuco). Disponível em https:// repositorio.ufpe.br/handle/123456789/33206 (17/03/2021).

»ASQ (2021). Learn about Quality: Fishbone Diagram. ASQ Learn about quality. Disponível em: https://asq.org/quality-resources/fishbone\#Use (15/03/2021).

»Astroza, S., Tirachini, A., Hurtubia, R., Carrasco, J. A., Guevara, A., Figueroa, M., y Torres, V. (2020). Mobility Changes, Teleworking, and Remote Communication during the COVID-19 Pandemic in Chile. Transport Findings, July/2020.

"Banister, D. (2007). The sustainable mobility paradigm. Transport policy, 15(2), 73-80.

"Benitez, F. (2016). Using the logical framework to analyze Transantiago. Disponível em https://wp.nyu.edu/mariafranciscabenitezbeas/wp-content/ uploads/sites/3428/2016/o6/Benitez_Transantiago.pdf (15/03/2021).

»Bouffanais, R., y Lim, S. S. (2020). Cities-try to predict superspreading hotspots for COVID-19. Nature, 583 (7816), 352-355.

"Bucsky, P. (2020). Modal share changes due to COVID-19: The case of Budapest. Transportation Research Interdisciplinary Perspectives, 8, 100141.

»Cheng, S. Z. L., Valdés, R. M. A., Comendador, V. F. G., y Sáez Nieto, F. J. (2019). A Case Study of Fishbone Sequential Diagram Application and ADREP Taxonomy Codification in Conventional ATM Incident Investigation. Symmetry, 11(4), 491.

»Couillard, J., Garon, S., y Riznic, J. (2009). The logical framework approachmillennium. Project Management Journal, 40(4), 31-44.

»Dai, J., Liu, Z., y Li, R. (2021). Improving the subway attraction for the postCOVID-19 era: The role of fare-free public transport policy. Transport Policy, 103, 21-30.

» Eisenmann, C., Nobis, C., Kolarova, V., Lenz, B., y Winkler, C. (2021). Transport mode use during the COVID-19 lockdown period in Germany: The car became more important, public transport lost ground. Transport Policy, 103, 60-67.

» Gaskin, D. J., Zare, H., y Delarmente, B. A. (2021). Geographic disparities 
in COVID-19 infections and deaths: The role of transportation. Transport policy, 102, 35-46.

" Gasper, D. (2000). Evaluating the 'logical framework approach'towards learningoriented development evaluation. Public administration and development, 20(1), 17-28.

" Gkiotsalitis, K., y Cats, O. (2020). Public transport planning adaption under the COVID-19 pandemic crisis: literature review of research needs and directions. Transport Reviews, 1-19.

»Hausler, S., Heineke, K., Hensley, R., Möller, T., Schwedhelm, D., y Shen, P. (2020). The impact of COVID-19 on future mobility solutions. McKinsey Center for Future Mobility.

» Heineke, K., Kampshoff, P., Moller, T., Wu, T. (2020). From no mobility to future mobility: Where COVID-19 has accelerated change. Mckinsey Center for Future Mobility. Disponível em https://www.mckinsey.com/industries/automotiveand-assembly/our-insights/from-no-mobility-to-future-mobility-where-covid19-has-accelerated-change (16/03/2021).

"Hiselius, L. W., y Arnfalk, P. (2021). When the impossible becomes possible: COVID-19's impact on work and travel patterns in Swedish public agencies. European Transport Research Review, 13(1), 1-10.

» Holden, E., Banister, D., Gössling, S., Gilpin, G., y Linnerud, K. (2020). Grand Narratives for sustainable mobility: A conceptual review. Energy Research y Social Science, 65, 101454.

» Ilie, G., y Ciocoiu, C. N. (2010). Application of fishbone diagram to determine the risk of an event with multiple causes. Management research and practice, 2(1), 1-20.

» Lima, G. C. L. S., Schechtman, R., Brizon, L. C., Figueiredo, Z. M. (2020). Transporte público e COVID-19. O que pode ser feito? Centro de Estudos em Regulação e Infraestrutura da Fundação Getúlio Vargas (FGV CERI).

" MDT (2020). Movimento Nacional pelo Direito ao Transporte Público de Qualidade para Todos. Diário do Transporte. Disponível em: https:// diariodotransporte.com.br/2020/04/02 (20/03/2021).

»Moufad, I., y Jawab, F. (2017). Multi-criteria analysis of urban public transport problems: the city of Fes as a Case. International Journal of Scientific y Engineering Research, 8(1).

»NTU (2020). O vírus que atropelou o Brasil. NTU. Disponível em: https:// www.ntu.org.br/novo/NoticiaCompleta.aspx?idArea $=10 y i d$ Noticia $=1364$ (13/03/2021).

» NTU, FABUS, ANFAVEA, Fórum dos Secretários e Dirigentes da Mobilidade Urbana, ANTP (2020). Como ter um Transporte Público Eficiente, Barato e com Qualidade na sua cidade. Portal de Mobilidade Urbana Sustentável. Disponível em https://www.mobilize.org.br/midias/pesquisas/transporte-publico-naseleicoes-2020.pdf (20/03/2021).

» Oum, T. H., y Wang, K. (2020). Socially optimal lockdown and travel restrictions for fighting communicable virus including COVID-19. Transport Policy, 96, 94-100.

» Rodrigues, L. (2020). Impacto da Covid-19 nas Políticas Públicas de Mobilidade Urbana. Associação Nacional de Especialistas em Políticas Públicas e Gestão Governamental - ANESP. Disponível em: http://anesp.org.br/todas-asnoticias/2020/4/22/impacto-da-covid-19-nas-polticas-pblicas-de-mobilidadeurbana (13/03/2021). 
» Russo, F., y Rindone, C. (2008). Safety of users in road evacuation: the logical framework approach in evacuation planning. WIT Transactions on the Built Environment, 101, 751-760.

» Saadat, S., Rawtani, D., y Hussain, C. M. (2020). Environmental perspective of COVID-19. Science of the Total Environment, 138870.

"Slameto, S. (2016). The Application of Fishbone Diagram Analisis to Improve School Quality. Dinamika Ilmu: Jurnal Pendidikan, 16(1), 59-74.

»Swiss Agency for Development and Cooperation (SDC). The Five Planning Stages of the Logical Framework Approach. Module 2: Planning for Results. Disponível em: http://deza-pcmi-lernbuch-3.prod2.lernetz.ch/module-2-en (14/03/2021).

» Tirachini, A., y Cats, O. (2020). COVID-19 and public transportation: Current assessment, prospects, and research needs. Journal of Public Transportation, 22(1), 1.

» UITP (2020a). Public transport authorities and COVID-19: impact and response to a pandemic. International Association of Public Transport - UITP. Disponível em https://www.lek.com/sites/default/files/PDFs/COVID19-public-transportimpacts.pdf (13/03/2021).

» UITP (2020b). COVID-19 Pandemic - Resuming public transport services post-lockown. International Association of Public Transport - UITP. Disponível em https://www.uitp.org/publications/covid-19-pandemic-resuming-publictransport-services-post-lockdown (13/03/2021).

» Vickerman, R. (2021). Will Covid-19 put the public back in public transport? A UK perspective. Transport Policy, 103, 95-102.

»Zhang, J. (2020). Transport policymaking that accounts for COVID-19 and future public health threats: A PASS approach. Transport policy, 99, 405-418. 


\section{O APÊNDICE A}

\section{PALESTRANTES, DEBATEDORES E INSTITUIÇÕES REPRESENTADAS}

1ํ) "O Futuro do Transporte Público Pós Pandemia" (21/05/2020). Prof. Mauricio Pina, Diretor de Planejamento do Consórcio de Transporte Metropolitano da RMR; Prof. Dr. Anísio Brasileiro, UFPE, Prof. Dr. Nilton Andrade, UFPB; Prof. Dr. Joaquim Aragão, UNB; Prof. Dr. Romulo Orrico, UFRJ, Prof. Dr. Enilson Santos, UFRN; Prof. Dr. Mauricio Andrade, Prof. Dr. Leonardo Meira, Profa. Dra. Viviane Falcão, UFPE e Prof. Dra. Jessica de Lima, UFAL.

$2^{\circ}$ ) “Como será a demanda do transporte público pós pandemia” (04/06/2020). Profa. Dra. Rosário Macário, Instituto Técnico Superior de Lisboa; Eng. Jurandir Fernandes, representante da UITP para a América Latina, Prof. MSc. Mauricio Pina, Diretor de Planejamento do Consórcio de Transporte Metropolitano da RMR, Eng. Fernando Bandeira, Presidente do Sindicato das Empresas de Transportes de Passageiros de Pernambuco; Guilbert Araújo representante da Ameciclo; Eng. Carlos Batinga Ex-Secretário de Mobilidade Urbana de João Pessoa, Prof. Dr. Joaquim Aragão, UNB; Prof. Dra. Maria Leonor Maia, UFPE; Prof. Dra. Andrea Gutierrez, Universidade de Buenos Aires, Prof. Dra. Rosa Ocaña, Universidad Simon Bolivar, Caracas; Helena Cibilis, Presidente da ANPET, Nazareno Afonso, Presidente do Instituto MDT; Eng. Marilia Pina, Diretora do Instituto da Cidade Pelópidas da Silveira.

$3^{\circ}$ ) "A crise do Covid-19: o que fazer de imediato para evitar o colapso do transporte público", (18/06/2020). Eng. Julian Sastre, Presidente do Instituto de Mobilidade Espanhol, Madri; Dr.Carlos Alberto Contreras Montoya, membro da Junta Diretiva do Conselho de Segurança Viária e Presidente da Comissão Técnica de Transportes e Subdiretor da División de Transportes do MOPT da Costa Rica; Eng. Otavio Vieira da Cunha, Presidente da Associação Nacional das Empresas de Transportes Urbanos -NTU, Eng.Luiz Carlos Montovani Nespoli, Secretario Executivo da ANTP; Dr. Marcelo Brutus, Secretario de Desenvolvimento Urbano do Estado de Pernambuco.

$4^{\circ}$ ) “As experiências dos órgãos gestores de transporte público frente a pandemia”, 02/07/2020. Dr. Francisco Javier Gomez López, Diretor de Planejamento estratégico e de Exploração do Consorcio Regional de Transportes de Madri; Dr.Luiz Alberto Saboia, Secretario Executivo de Conservação e Serviços Públicos da Prefeitura de Fortaleza; Adv. Matheus Moura, Diretor de Transporte da Secretaria de Mobilidade da Prefeitura de Salvador; Eng. Fabio Damasceno, Secretário de Mobilidade e infraestrutura do Governo do Espirito Santo; Eng. Bejamin Kennedy, Presidente da Companhia Metropolitana de Transporte Coletivo de Goiania; Adm.Celio Bouzada, Presidente da Empresa de Transportes e Trânsito de Belo Horizonte- BHTRANS; Eng. Rodrigo Tortoriello, Secretário Extraordinário de Mobilidade Urbana da Prefeitura de Porto Alegre e Presidente do Forum de Secretários de Transportes Urbanos.

$5^{\circ}$ ) “Cidades e Mobilidade: rediscutindo a relação diante da pandemia”,16/07/2020. Prof. Dr. Mariano Perez Humanes e Natalia De'Carli, da Universidade de Sevilha, Espanha; Arq./Urb. Marcelo Inacios, responsável pelo Estudos Econômicos no âmbito do Plano Diretor Estratégico e de Operações Consorciadas da Prefeitura de São Paulo; Arq./Urb. Geraldo Marinho, ex-Prof. Da Escola de Arquitetura e Urbanismo da UFPE, responsável pela Elaboração do PDUI da RMR conduzido pela Condepe/Fidem; Arq./Urb. Rebeca Vieira de Melo, consultora em planejamento urbano.

$\left.6^{\circ}\right)$ "Os desafios sociais e políticos trazidos pela pandemia para as cidades e o transporte público”, (30/07/2020). Enga. Luciana Santos, Vice-Governadora de Pernambuco; Senador Humberto Costa, médico, jornalista, especialista em Ciência Política; Prof. Dr. Anísio Brasileiro, UFPE; Prof. Manoel Moraes, coordenador da Cátedra UNESCO/UNICAP de Direitos Humanos Dom Helder Câmara; Adv. Antônio Celestino da Silva Neto, Advogado do Programa de Direito à Cidade do Centro Dom Helder Câmara de Estudos e Ação Social-CENDHEC.

$7^{\circ}$ ) “Ações imediatas para uma mobilidade segura até a imunização da população.", 13/08/2020. Palestrantes: Prof. Dr. Ing. Oswaldo Lima Neto, UFPE; Prof. Dr. Mauricio Andrade, UFPE e Prof.Dr. Enilson Santos. Discussão da MML para análise das ações e estratégias propostas. 
8) "As reformas necessárias para tornar nossas cidades e o transporte público sustentáveis e resilientes”, 27/08/2020. Palestrantes: Prof. Dr. Ing. Oswaldo Lima Neto, UFPE; Prof. Dr. Mauricio Andrade, UFPE e Prof. Dr. Enilson Santos. Discussão da MML para validação das propostas revisadas.

\section{Mauricio Oliveira de Andrade / mauandrade@gmail.com}

Engenheiro Civil pela Universidade Federal de Pernambuco (UFPE-1978), Mestre e Doutor em Engenharia Civil - Transportes (UFPE-2006 e 2012). Professor e pesquisador na UFPE. Bolsista de produtividade do CNPq - PQ 2. Tem pesquisas nas áreas de Gestão das Infraestruturas, Engenharia Econômica, Economia dos Transportes e Métodos Econométrico, além de 30 anos de experiência na área de consultoria de engenharia (1979 a 2009), com ênfase em Engenharia de Transportes

\section{Oswaldo Cavalcanti da Costa Lima Neto / oswaldolimaneto@yahoo.com.br}

Possui graduação em Engenharia Civil pela Universidade Federal de Pernambuco (1972), mestrado em Engenharia Civil pela Pontifícia Universidade Católica do Rio de Jancasa e eiro (1975) e doutorado pela RWTHA Aachen University (1982). Atualmente é professor titular aposentado da UFPE, continua atuando junto a Área de Transporte e Gestão das Infraestruturas nos temas de: mobilidade urbana sustentável, analise espacial em centralidades urbanas, planejamento e gestão de transporte urbano e público.

\section{Ligia Rabay / ligi.rabay@gmail.com}

Engenheira Civil pela Universidade Federal da Paraíba (2016). Mestre em Engenharia Civil com ênfase em Transportes e Gestão das Infraestruturas Urbanas pela Universidade Federal de Pernambuco - UFPE (2019). Doutorado em andamento na UFPE na área de Transportes (iniciado em 2019). Atua principalmente nos seguintes temas: transporte público, gerenciamento da demanda, economia dos transportes e mobilidade urbana. Professora substituta na Universidade Federal do Rio Grande do Norte. 